\title{
The single nucleotide polymorphism site of aquaporin-4 gene in patients with neuromyelitis optica
}

\author{
QING-SONG WANG ${ }^{*}$, HONG-QIONG XIAO*, HUA-XIAN CHEN, YAN-PING LIU and XU-DONG DING \\ Department of Rehabilitation Medicine, Xiangyang No. 1 People's Hospital, \\ Hubei University of Medicine, Xiangyang, Hubei 441000, P.R. China
}

Received May 29, 2017; Accepted September 21, 2017

DOI: 10.3892/etm.2017.5267

\begin{abstract}
The single nucleotide polymorphism (SNP) site within the aquaporin (AQP)-4 gene exons and its possible role in the pathogenesis of neuromyelitis optica (NMO) were studied. From March 2010 to June 2012, 72 patients with NMO from Xiangyang No. 1 People's Hospital, Hubei University of Medicine were enrolled in the NMO group. At the same time, 80 patients with multiple sclerosis (MS) were enrolled in our study as the MS group. Blood samples were collected and DNA was extracted for analysis of SNP sites of AQP4 gene. Specific site-directed mutagenesis method was used for site-directed mutagenesis on plasmid enhanced green fluorescence protein carrying $A Q P 4$ gene. Mutant plasmids were constructed and used for transfecting cell lines. The differences of anti-AQP4 antibody level in the cell line were analyzed. The possible correlation between AQP4 gene SNP sites and the pathogenesis of NMO were analyzed. In the NMO group, $6 \mathrm{SNP}$ sites in AQP4 gene were located in exons 2 and 5. These included R108T, I110N, E280R, D281R, P295R and E317M. There was no SNP site in exons 1, 3 and 4. In the MS group, no SNP site was found in AQP4 gene. R108T, I110N, R108T/I110N, E280R/D281R, P295R and E317M cell lines were constructed in the NMO group, and anti-AQP4 antibody in the serum was compared between R108T/I110N, E280R/D281R and E317M cell lines and the original HEK293T cell line. The difference was statistically significant $(\mathrm{P}<0.05)$. The positive rate of anti-AQP4 antibody titer in serum was compared between R108T, I110N, R108T/I110N, E280R/D281R, P295R and E317M cell lines in the NMO group and the original cell line in the MS group.
\end{abstract}

Correspondence to: Dr Xu-Dong Ding, Department of Rehabilitation Medicine, Xiangyang No. 1 People's Hospital, Hubei University of Medicine, 15 Jiefang Road, Xiangyang, Hubei 441000, P.R. China

E-mail: ding_xudong1@163.com

*Contributed equally

Key words: neuromyelitis optica, aquaporin-4, single nucleotide, polymorphism
In conclusion, SNP sites in AQP4 gene in patients with $\mathrm{NMO}$ may lead to some conformational changes in AQP4 protein. This affects the antigenicity of AQP4 protein. The different intensity of antigen-antibody reaction may cause the differences of titer observed between the different mutant cell lines.

\section{Introduction}

In 1894, neuromyelitis optica (NMO), an autoimmune disease, was first reported by Devic (1). This disease affects the optic nerve and the spinal cord. In 2004, Lennon et al found a correlation between NMO IgG and NMO disease (2). In 2005, the same research group confirmed that aquaporin (AQP)-4 was the target of NMO IgG (3). The identification of this antibody clarified the line differences between NMO and multiple sclerosis (MS).

At present, the study on NMO and MS involves racial distribution, immune mechanism, pathology, treatment and prognosis $(4,5)$. In the present study, the single nucleotide polymorphism (SNP) sites in AQP4 gene in patients suffering from NMO were studied. At the same time, cell lines with different variation sites of AQP4 gene were established, and these cell lines expressed different AQP4 protein. We analyzed the correlation between different variation sites of $A Q P 4$ gene and the mechanism of NMO.

\section{Materials and methods}

Clinical data. From March 2010 to June 2012, 72 patients with NMO (including 16 cases of patients with high-risk syndrome) from Xiangyang No. 1 People's Hospital, Hubei University of Medicine (Hubei, China) were enrolled in this study as the NMO group. In this group, there were 14 males and 58 females, with ages ranging from 12 to 60 years (average age, $40.6 \pm 13.0$ years). Expanded disability status scale (EDSS) in the NMO group ranged from 3.5 to 7.5 (average, 4.3 \pm 1.6 ). At the same time, 80 patients with MS were enrolled in the MS group. In the MS group, 36 patients were male and 44 were female, with an age range of 18 to 66 years (average age, $37.7 \pm 11.8$ years). EDSS in the MS group was from 2.5 to

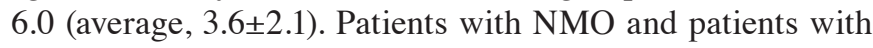
high-risk syndrome were identified using the Wingerchuk's diagnostic criteria (6), and patients with MS were identified using the McDonald's diagnostic criteria (7). 
Table I. Primer sequence, melting temperature and amplified fragment length of AQP4 gene exon.

\begin{tabular}{|c|c|c|c|}
\hline Exons & Primer sequence & $\begin{array}{c}\text { Melting } \\
\text { temperature }\left({ }^{\circ} \mathrm{C}\right)\end{array}$ & $\begin{array}{l}\text { Amplified fragment } \\
\text { length (bp) }\end{array}$ \\
\hline 1 & $\begin{array}{l}\text { U: 5'-CAGGCAATGAGAGCTGCAC-3' } \\
\text { D: 5'-ATCCCGGTTTTCTACTTTGACA-3' }\end{array}$ & 60.5 & 122 \\
\hline $2-1$ & $\begin{array}{l}\text { U: 5'-GTAGTGGCTTCTGATGCTG-3' } \\
\text { D: 5'-AAGAGTAGAGGGAAACGA-3' }\end{array}$ & 50.8 & 234 \\
\hline $2-2$ & $\begin{array}{l}\text { U: 5'-TGGTTCTCATCTCCCTTTGCT-3' } \\
\text { D: 5'-GATCCTGAGGTTCGAAGAACG-3' }\end{array}$ & 56.9 & 284 \\
\hline 3 & $\begin{array}{l}\text { U: 5'-TGTCATCGAAAATACTCTTG-3' } \\
\text { D: 5'-TCATTCAAAGGTTCAGGTAA-3' }\end{array}$ & 48.8 & 238 \\
\hline 4 & $\begin{array}{l}\text { U: 5'-GTAGCCCTGTTTCAGCAAT-3' } \\
\text { D: 5'-ATCCCTTTCTTATCGTGTCT-3' }\end{array}$ & 49.2 & 294 \\
\hline 5 & $\begin{array}{l}\text { U: 5'-TCGTTTTAAAGAAGCCTTCAGC-3' } \\
\text { D: 5'-ATCTTCTAGCGTGACTTTCGTC-3' }\end{array}$ & 60.0 & 216 \\
\hline
\end{tabular}

U, upstream; D, downstream.

Tumor tissues, provided by the Department of Rehabilitation Medicine, Xiangyang No. 1 People's Hospital, Hubei University of Medicine, belonged to a 62 year-old-male patient with meningioma. This study was carried out under the approval of the Ethics Committee of the hospital, and patients were fully informed and signed a formal written authorization. All the patients were independently diagnosed by at least two deputy chief physicians from the Department of Neurology.

Materials. HEK293T cells were purchased from the Cell Bank of Type Culture Collection of Chinese Academy of Sciences (Shanghai, China), and the recombinant plasmid pEGFP-N was provided by Clontech Laboratories, Inc. (Mountainview, CA, USA). G418, Lipofectamine ${ }^{\mathrm{TM}} 2000$ and goat anti-human IgG were supplied by Invitrogen; Thermo Fisher Scientific, Inc. (Waltham, MA, USA), while rabbit anti-human AQP4 polyclonal antibody and goat anti-rabbit IgG were purchased from Millipore; Merck \& Co., Inc. (Whitehouse Station, NJ, USA).

Equipment. We used a gradient polymerase chain reaction (PCR) amplification instrument (9,600 type), a high-speed refrigerated centrifuge (TGL-16G type), an electric thermostatic water bath (HH.WZ1 420 type), a spectrophotometer (Bio-Rad Laboratories, Inc., Hercules, CA, USA), a DNA gel imaging analysis system (Olympus, Tokyo, Japan), a steady flow electrophoresis (DYY-III-5 type), a horizontal tank (33A type), a cryogenic refrigerator, a flow cytometry instrument, a $5 \% \mathrm{CO}_{2}$ cell incubator, an Olympus fluorescence microscope and a genetic analyzer equipment (310 type).

\section{Methods}

PCR and sequencing. Prior to relevant treatment of glucocorticoid or immunosuppressant, $5 \mathrm{ml}$ fasting venous blood was collected from patients in ethylene diamine tetraacetic acid anticoagulative tubes and stored at $-80^{\circ} \mathrm{C}$. Of each blood sample, $500 \mu \mathrm{l}$ was centrifuged for $10 \mathrm{~min}$ at $4^{\circ} \mathrm{C}$ at $8,300 \mathrm{x} \mathrm{g}$ to separate the serum. Genomic DNA was extracted from blood cells using the phenol-chloroform method. The target gene segments were exons 1, 2, 3, 4 and 5 as well as their flanking sequences in the AQP4 gene (NC_000018). Target gene was amplificated using PCR. Primer sequence, melting temperature and amplified fragment length are presented in Table I. Chromas 2 (Technelysium Pty. Ltd., South Brisbane, QLD, Australia) software was applied to analyze sequencing results.

Construction of the plasmid. SNP sites in AQP4 gene were identified after the analysis of sequences. RNA was extracted from tumor tissue and reverse transcription was conducted on human AQP4 full-length cDNA (AQP4 subtype A, GenBank accession number NM_001650). The primers used were: Upstream primer (5'-TTCTAGACCACCATGAGTGACAG ACCCAC-3', containing the XbaI enzyme cutting site of TCT AGA) and downstream primer 5'-CGTGTACATCATACTG AAGACAATACCTCTCCAG-3', containing the BsrGI enzyme cutting site of TGTACA).

Full human AQP4 cDNA was amplified using PCR. AQP4 gene segment was cloned into a pEGFP-N1 plasmid vector, and the recombinant plasmid was labeled as pEGFP-N-AQP4. pEGFP-N-AQP4 plasmid was sequenced for confirmation.

Site-directed mutagenesis and construction of cell lines. To investigate the association between variation point and NMO, site-directed mutagenesis was conducted in the corresponding sites in the pEGFP-N-AQP4 plasmid to construct six types of plasmid with $A Q P 4$ gene mutation. This included single point mutation and double point mutations. AQP4 cDNA was sequenced after site-directed mutagenesis to confirm the variation points of nucleotides and amino acids. The latter contained R108T, I110N, E280R, D281R, P295R and E317M. Using liposome Lipofectamine ${ }^{\mathrm{TM}}$ 2000, HEK293T cells were transfected with different plasmids. Dulbecco's modified 
Table II. The analysis of SNP sites of AQP4 gene exon.

\begin{tabular}{|c|c|c|c|c|c|c|c|}
\hline $\begin{array}{l}\text { Sequence } \\
\text { number }\end{array}$ & Exons & SNP sites & $\begin{array}{l}\text { Changes of } \\
\text { nucleic acid }\end{array}$ & $\begin{array}{c}\text { Amino } \\
\text { acid sites }\end{array}$ & $\begin{array}{l}\text { Change of } \\
\text { amino acid }\end{array}$ & $\begin{array}{l}\text { NMO group } \\
\quad(n=72)\end{array}$ & $\begin{array}{c}\text { MS group } \\
(n=80)\end{array}$ \\
\hline 1 & 2 & 3447 & $\mathrm{G} \rightarrow \mathrm{C}$ & $108 \mathrm{R}$ & $\mathrm{R} \rightarrow \mathrm{T}$ & 4 & 0 \\
\hline 2 & 2 & 3453 & $\mathrm{~T} \rightarrow \mathrm{A}$ & 110I & $\mathrm{I} \rightarrow \mathrm{N}$ & 2 & 0 \\
\hline 3 & 5 & 9414 & $\mathrm{G} \rightarrow \mathrm{A}$ & $280 \mathrm{E}$ & $\mathrm{E} \rightarrow \mathrm{R}$ & 9 & 0 \\
\hline 4 & 5 & 9416 & $\mathrm{C} \rightarrow \mathrm{G}$ & 281D & $\mathrm{D} \rightarrow \mathrm{R}$ & 5 & 0 \\
\hline 5 & 5 & 9458 & $\mathrm{~T} \rightarrow \mathrm{G}$ & $295 \mathrm{P}$ & $\mathrm{P} \rightarrow \mathrm{R}$ & 1 & 0 \\
\hline 6 & 5 & 9524 & $\mathrm{G} \rightarrow \mathrm{T}$ & $317 \mathrm{E}$ & $\mathrm{E} \rightarrow \mathrm{M}$ & 4 & 0 \\
\hline
\end{tabular}

SNP, single nucleotide polymorphism; R, arginine; T, threonine; I, isoleucine; N, asparagine; E, glutamic acid; D, aspartic acid; P, proline; M, methionine; NMO, neuromyelitis optica; MS, multiple sclerosis.

Table III. Analysis of anti-AQP4 antibody titer in serum in patients with NMO.

\begin{tabular}{|c|c|c|c|c|c|}
\hline Groups & Cases & $\begin{array}{l}\text { Anti-AQP4 antibody } \\
\text { titer in serum }\end{array}$ & $\begin{array}{l}\text { Logarithmic transformation } \\
\qquad(\text { mean } \pm \text { SD })\end{array}$ & t-value ${ }^{a}$ & P-value \\
\hline Original cell strain & 72 & $1: 1,000-1: 2,500$ & $3.17 \pm 0.54$ & - & - \\
\hline $\mathrm{R} 108 \mathrm{~T}$ & 72 & $1: 1,000-1: 2,000$ & $3.14 \pm 0.33$ & 1.045 & 0.57 \\
\hline I110N & 72 & $1: 1,000-1: 1,500$ & $3.18 \pm 0.31$ & 0.765 & 0.72 \\
\hline $\mathrm{R} 108 \mathrm{~T} / \mathrm{I} 110 \mathrm{~N}$ & 72 & $1: 512-1: 1,500$ & $3.02 \pm 0.21$ & 4.132 & 0.04 \\
\hline E280R/D281R & 72 & $1: 512-1: 1,500$ & $3.03 \pm 0.09$ & 4.077 & 0.04 \\
\hline P295R & 72 & $1: 1,000-1: 2,000$ & $3.11 \pm 0.41$ & 0.825 & 0.68 \\
\hline E317M & 72 & $1: 512-1: 1,500$ & $3.05 \pm 0.16$ & 4.875 & 0.03 \\
\hline
\end{tabular}

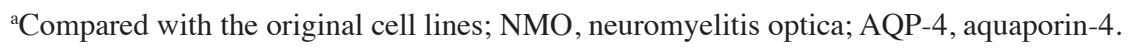

Eagle's medium (0.8 g/l G418) was used and viable cells were recultured for sorting by flow cytometry. Six kinds of cells with corresponding AQP4 gene mutations and stable expression (GFP expression rate of cells reached approximately 80\%) were established. At the same time, the pEGFP-N-AQP4 plasmid was used as the original plasmid to transfect HEK293T cells to establish the original cell line.

Anti-AQP4 antibody titer in serum. The method of Takahashi et al (8) was used to measure anti-AQP4 antibody titer in the serum. Serum was then diluted (at ratios of 1:2, 1:4, 1:8, 1:16, 1:32, 1:64, 1:128, 1:256, 1:512, 1:1 000, 1:1,500, $1: 2,000,1: 2500,1: 3,000,1: 3,500$ and 1:4,000). Antibody titer equal or greater than 1:256 was considered positive. For the positive control, rabbit anti-human antibody was used. Rabbit anti-huamn AQP4-polyclonal antibody was used as the primary antibody (1:2,000; cat. no. sc-20812) and goat anti-rabbit IgG was used as the secondary polyclonal antibody (1:1,000; cat. no. sc-2004) (both from Santa Cruz Biotechnology, Inc., Santa Cruz, CA, USA). Absorbance of $>0.31$ was considered as positive, while $<0.31$ was considered as negative. Anti-AQP4 antibody titer in the serum was measured after the cell lines stably expressed AQP4 and GFP.

Statistical analysis. We used SPSS 11.5 (SPSS, Inc., Chicago, IL, USA) statistical software for analysis. After logarithmic conversion, the anti-AQP4 antibody levels in the serum were expressed by mean \pm standard deviation (mean \pm SD). A t-test was used for the comparison between two groups and $\chi^{2}$ test was used for countable data. $\mathrm{P}<0.05$ was considered to indicate a statistically significant difference.

\section{Results}

Analysis of SNP sites of AQP4 gene exon. DNA sequencing results showed that SNP sites were located in exons 2 and 5 in the AQP4 gene. No SNP sites were detected in the other exons. No SNP sites were detected in the AQP4 gene in the MS group (Table II).

Analysis of anti-AQP4 antibody titer in serum in patients with NMO. No significant differences were detected in anti-AQP4 antibody titers in R108T, I110N, P295R cell lines and the original cell line $(\mathrm{P}>0.05)$. On the other hand, significant differences in anti-AQP4 antibody titer in serum were detected between R108T/I110N, E280R/D281R, E317M and the original cell line $(\mathrm{P}<0.05)$ (Table III).

Comparison of the positive rate of anti-AQP4 antibody titer in serum between patients with NMO and patients with $M S$. The results showed significant differences between the positive rate of anti-AQP4 antibody titer in the serum 
Table IV. Comparison of positive rate of anti-AQP4 antibody titer in serum between patients with NMO and patients with MS [n (\%)].

\begin{tabular}{lcccccccc}
\hline Groups & Cases & $\begin{array}{c}\text { Original cell line, } \\
\mathrm{n}(\%)\end{array}$ & $\begin{array}{c}\mathrm{R} 108 \mathrm{~T}, \\
\mathrm{n}(\%)\end{array}$ & $\begin{array}{c}\mathrm{I} 110 \mathrm{~N}, \\
\mathrm{n}(\%)\end{array}$ & $\begin{array}{c}\mathrm{R} 108 \mathrm{~T} / \mathrm{I} 110 \mathrm{~N}, \\
\mathrm{n}(\%)\end{array}$ & $\begin{array}{c}\mathrm{E} 280 \mathrm{R} / \mathrm{D} 281 \mathrm{R}, \\
\mathrm{n}(\%)\end{array}$ & $\begin{array}{c}\text { P295R } \\
\mathrm{n}(\%)\end{array}$ & $\begin{array}{c}\mathrm{E} 317 \mathrm{M}, \\
\mathrm{n}(\%)\end{array}$ \\
\hline $\mathrm{NMO}$ & 72 & $54(75.0)$ & $48(66.7)$ & $42(58.3)$ & $44(61.1)$ & $41(56.9)$ & $45(62.5)$ & $40(55.6)$ \\
$\mathrm{MS}$ & 80 & $4(5.0)$ & $3(3.8)$ & $4(5.0)$ & $3(3.8)$ & $3(3.8)$ & $5(6.2)$ & $2(2.5)$ \\
$\chi^{2}$ test & & 75.749 & 64.491 & 48.578 & 55.719 & 51.516 & 54.003 & 52.616 \\
P-value & $<0.01$ & $<0.01$ & $<0.01$ & $<0.01$ & $<0.01$ & $<0.01$ & $<0.01$ \\
\hline
\end{tabular}

NMO, neuromyelitis optica; MS, multiple sclerosis; AQP-4, aquaporin-4.

between patients in the NMO group and those in the MS group (Table IV).

\section{Discussion}

Many factors, including external and internal factors, may cause the incidence of NMO. In the present study, we analyzed $\mathrm{NMO}$ at the genetic level. $A Q P 4$ gene contains 5 exons, which can encode two types of proteins: i) M1 (31 kDa) and ii) M23 type $(34 \mathrm{kDa})$. In the brain tissue, M23 protein accounts for a larger proportion and is highly expressed in the vicinity of blood and brain-cerebrospinal barrier (9). The M23 expression level is the highest in the astrocytes (10-13). AQP4 protein is also expressed in other parts, such as the ependymal region around the optic nerve head and ventricular system. It has been previously demonstrated that the parts with higher expression levels had good consistency with the predilection sites of NMO (2,14-17).

Several studies have been conducted on the relationship between HLA and MS at the genetic level, however, there are only few studies reporting on the AQP4 expression level $(18,19)$. There are studies showing that changes in the AQP4 expression level were associated with the pathogenesis of several diseases. Sorani et al analyzed the AQP4 gene and identified 24 SNP sites, including 9 SNP sites, located in the coding region (20). Site-directed mutagenesis showed that the water permeability of AQP4 protein correlated with these sites. Kleffner et al analyzed the AQP4 gene in patients suffering from middle cerebral artery occlusion (MCAO), and identified 10 SNP sites (21). It was shown that the severity of cephaledema after MCAO was closely related to the rs9951307 site of AQP4 gene. To the best of our knowledge, few studies are available on the role of $A Q P 4$ gene in NMO. Previous studies showed that changes in AQP4 expression levels correlated with the pathogenesis of NMO and MS (22). It has been shown that the mechanism controlling the changes in the AQP4 expression level depend on 1,003 point mutations (A-G) in AQP4 gene promoter -0 and insertion mutation between 400 and 401 site in AQP4 gene promoter -1. Matiello et al reported that they did not find any SNP sites in the AQP4 gene (23). Results obtained from these studies remain controversial.

It was shown that mutations related to amino acid (His139Tyr and Trp144Term) may induce the occurrence of hereditary spastic paraplegia (24). We showed that in the NMO group, there were six SNP sites in AQP4 gene located in exons 2 and 5, and mutations were non-synonymous mutations. Mutations resulted in changes in amino acid, and these changes included R108T, I110N, E280R, D281R, P295R and E317M. No significant differences in the anti-AQP4 antibody levels were detected between R108T, I110N, P295R cell lines and the original cell line $(\mathrm{P}>0.05)$. However, there were significant differences between R108T/I110N, E280R/D281R, $\mathrm{E} 317 \mathrm{M}$ and the original cell line $(\mathrm{P}<0.05)$ (Table III). It has been shown that when AQP4 protein reacted with anti-AQP4 antibody, there were some differences between M1 (31 kDa) and M23 type (34 kDa) proteins. This led to larger differences on the detection of anti-AQP4 antibody in different cell lines (2). From another angle, the results confirmed that the changes in the expression levels had an effect on the combination strength of the antigen and antibody. Other studies showed that different parts of the AQP4 protein had different levels of antigenicity. The extracellular domain of AQP4 protein is the binding site for the anti-AQP4 antibody (9). Our results show that the SNP sites in $A Q P 4$ gene were not located in the extracellular domain of the AQP4 protein. However, whether this may potentially change the affinity of the extracellular segment has yet to be further studied.

At present, in China, the diagnosis standard of NMO is in accordance with the diagnostic standard of western countries. In this study, 6 kinds of cells with corresponding AQP4 gene mutation and original cell line were respectively put into the serum of patients with NMO to detect the positive rates of anti-AQP4 antibody titer.

Results showed that, in the NMO group, the positive rate of anti-AQP4 antibody titer in serum was $75 \%$, which was lower than the levels reported in previous studies (25). This difference can be explained as due to our target population was chosen among Chinese patients while in other reports, European patients were the target population. On the other hand, our study may have used different diagnosis standards. Therefore, it is imperative to establish a suitable diagnosis standard for NMO that can be applied on different populations in different countries. Our results also suggest that mechanisms of MS between patients with positive and those with negative anti-AQP4 antibody were different. Regarding the outcome and prognosis, the follow-up continues.

We showed that genetic changes may lead to changes in protein conformation, and these changes may affect antigenicity. Thus, exploring the pathogenesis of NMO from the gene level was a good research direction. There were some 
shortcomings in this study. There were only 5 exons in $A Q P 4$ gene and the detection scope was not comprehensive. Due to the limited number of patients, the information on the SNP sites was limited. In future, when the SNP site analysis is to be studied on the AQP4 gene exons, the detection should be carried out on the promoter region to complete the SNP site analysis. Thus, by studying more patients with NMO, the research scale can be expanded to prepare for the next step, the haplotype correlation analysis.

\section{References}

1. Devic E: Subacute myelitis complicated by optic neuritis. Bull Med 8: 1033-1034, 1894 (In French).

2. Lennon VA, Wingerchuk DM, Kryzer TJ, Pittock SJ, Lucchinetti CF, Fujihara K, Nakashima I and Weinshenker BG: A serum autoantibody marker of neuromyelitis optica: Distinction from multiple sclerosis. Lancet 364: 2106-2112, 2004.

3. Lennon VA, Kryzer TJ, Pittock SJ, Verkman AS and Hinson SR $\mathrm{IgG}$ marker of optic-spinal multiple sclerosis binds to the aquaporin-4 water channel. J Exp Med 202: 473-477, 2005.

4. Kira J: Neuromyelitis optica and opticospinal multiple sclerosis: Mechanisms and pathogenesis. Pathophysiology 18: 69-79, 2011

5. Lim BC, Hwang H, Kim KJ, Hwang YS, Cheon JE, Kim IO, Kim HJ and Chae JH: Relapsing demyelinating CNS disease in a Korean pediatric population: Multiple sclerosis versus neuromyelitis optica. Mult Scler 17: 67-73, 2011.

6. Wingerchuk DM, Lennon VA, Pittock SJ, Lucchinetti CF and Weinshenker BG: Revised diagnostic criteria for neuromyelitis optica. Neurology 66: 1485-1489, 2006.

7. Polman CH, Reingold SC, Edan G, Filippi M, Hartung HP, Kappos L,Lublin FD,MetzLM, McFarland HF, O'Connor PW, et al: Diagnostic criteria for multiple sclerosis: 2005 revisions to the 'McDonald Criteria'. Ann Neurol 58: 840-846, 2005.

8. Takahashi T, Fujihara K, Nakashima I, Misu T, Miyazawa I, Nakamura M, Watanabe S, Ishii N and Itoyama Y: Establishment of a new sensitive assay for anti-human aquaporin- 4 antibody in neuromyelitis optica. Tohoku J Exp Med 210: 307-313, 2006.

9. Hiroaki Y, Tani K, Kamegawa A, Gyobu N, Nishikawa K, Suzuki H, Walz T, Sasaki S, Mitsuoka K, Kimura K, et al: Implications of the aquaporin-4 structure on array formation and cell adhesion. J Mol Biol 355: 628-639, 2006.

10. Amiry-Moghaddam M, Xue R, Haug FM, Neely JD, Bhardwaj A, Agre P, Adams ME, Froehner SC, Mori S and Ottersen OP: Alpha-syntrophin deletion removes the perivascular but not endothelial pool of aquaporin-4 at the blood-brain barrier and delays the development of brain edema in an experimental model of acute hyponatremia. FASEB J 18: 542-544, 2004.

11. Cavazzin C, Ferrari D, Facchetti F, Russignan A, Vescovi AL, La Porta CA and Gritti A: Unique expression and localization of aquaporin-4 and aquaporin-9 in murine and human neural stem cells and in their glial progeny. Glia 53: 167-181, 2006.
12. Tomás-Camardiel M, Venero JL, Herrera AJ, De Pablos RM, Pintor-Toro JA, Machado A and Cano J: Blood-brain barrier disruption highly induces aquaporin- 4 mRNA and protein in perivascular and parenchymal astrocytes: Protective effect by estradiol treatment in ovariectomized animals. J Neurosci Res 80: 235-246, 2005.

13. Niu $\mathrm{CH}$ and Zhang $\mathrm{XH}$ : The research progress of pathogenesis and treatment strategy of neuromyelitis optica. Chin J Neuroimmunol Neurol 20: 208-211, 2013 (In Chinese).

14. Fujihara K: Neuromyelitis optica and astrocytic damage in its pathogenesis. J Neurol Sci 306: 183-187, 2011.

15. Pittock SJ, Weinshenker BG, Lucchinetti CF, Wingerchuk DM, Corboy JR and Lennon VA: Neuromyelitis optica brain lesions localized at sites of high aquaporin 4 expression. Arch Neurol 63: 964-968, 2006.

16. Pittock SJ, Lennon VA, Krecke K, Wingerchuk DM, Lucchinetti CF and Weinshenker BG: Brain abnormalities in neuromyelitis optica. Arch Neurol 63: 390-396, 2006.

17. Wingerchuk DM: Neuromyelitis optica: New findings on pathogenesis. Int Rev Neurobiol 79: 665-688, 2007.

18. Dean G, Yeo TW, Goris A, Taylor CJ, Goodman RS, Elian M, Galea-Debono A, Aquilina A,Felice A, Vella M, et al:HLA-DRB1 and multiple sclerosis in Malta. Neurology 70: 101-105, 2008.

19. McElroy JP, Cree BA, Caillier SJ, Gregersen PK, Herbert J, Khan OA, Freudenberg J, Lee A, Bridges SL Jr, Hauser SL, et al: Refining the association of MHC with multiple sclerosis in African Americans. Hum Mol Genet 19: 3080-3088, 2010.

20. Sorani MD, Zador Z, Hurowitz E, Yan D, Giacomini KM and Manley GT: Novel variants in human Aquaporin-4 reduce cellular water permeability. Hum Mol Genet 17: 2379-2389, 2008.

21. Kleffner I, Bungeroth M, Schiffbauer H, Schäbitz WR, Ringelstein EB and Kuhlenbäumer G: The role of aquaporin-4 polymorphisms in the development of brain edema after middle cerebral artery occlusion. Stroke 39: 1333-1335, 2008.

22. Mai WH, Hu XQ, Long YM, Lu ZQ, Peng FH and Wang YG: Associations of aquaporin-4 promoter polymorphism to multiple sclerosis and neuromyelitis optica in southern Chinese population. Chin J Neurol 45: 312-317, 2012.

23. Matiello M, Schaefer-Klein JL, Hebrink DD, Kingsbury DJ, Atkinson EJ, Weinshenker BG and NMO Genetics Collaborators: Genetic analysis of aquaporin-4 in neuromyelitis optica. Neurology 77: 1149-1155, 2011.

24. Stevanin G, Ruberg M and Brice A: Recent advances in the genetics of spastic paraplegias. Curr Neurol Neurosci Rep 8: 198-210, 2008

25. Waters P, Jarius S, Littleton E, Leite MI, Jacob S, Gray B, Geraldes R, Vale T, Jacob A, Palace J, et al: Aquaporin-4 antibodies in neuromyelitis optica and longitudinally extensive transverse myelitis. Arch Neurol 65: 913-919, 2008. 